\title{
Mediastinal Mass and Superior Vena Cava Obstruction Masquadering as Lung Carcinoma -A Case Report
}

\author{
Jyoti Bajpai ${ }^{1}$ and Surya Kant ${ }^{1 *}$ \\ King George Medical University, India
}

Submission: March 15, 2017; Published: August 02, 2017

*Corresponding author: Surya Kant, King George Medical University, Lucknow, India, Tel: 9415016858; Email: skantpulmed@gmail.com

\begin{abstract}
Pulmonary tuberculosis has different types of radiological presentations. Mediastinal mass with superior vena cava obstruction mostly points out towards malignancy. We are reporting a case 40 years old a male alcoholic, smoker, with known case of diabetes mellitus presented with a mediastinal mass with effusion and cavitating lesions as a case of pulmonary tuberculosis. Sputum cytology and bronchoscopy biopsy suggestive of tuberculosis. Four drug anti tubercular therapy started and patient got relieved in his symptoms after one month.

Keywords: Pulmonary tuberculosis; Mediastinal mass; Superior vena cava obstruction; Endobronchial biopsy
\end{abstract}

\section{Introduction}

Pulmonary tuberculosis is a greatest health problem of the world. Around 9.6 million cases of tuberculosis are reported worldwide annually [1]. Pulmonary tuberculosis shows different radiological presentations, pretending all the other pathological formations of the lung and clinical difficulties for diagnosis [2]. Different type of bacterial and fungal infection, bronchogenic carcinoma are such common diseases which can be imitating as pulmonary tuberculosis because of non-specific symptoms and similar radiological findings. Symptoms such as fever, cough, hemoptysis, weight loss and loss of appetite are common to both tuberculosis and lung cancer [3]. We are presenting a case of pulmonary tuberculosis that pretended as a lung cancer in the way it had presented which required bronchial biopsy and sputum smear for AFB for final diagnosis.

\section{Case History}

A 40 year old male chronic alcoholic and smoker presented to our emergency department with complaints of fever for last two months, cough with expectoration for two months, breathlessness for last one months and facial puffiness for last 15 days. Routine lab investigations were done. Sputum for acid-fast bacilli (AFB) was positive, HIV non-reactive. His haematological and biochemical parameters was within normal limits. On general examination his neck veins were prominent and facial swelling were seen. These findings were indicative of superior vena cava obstruction. CXR suggestive of right sided intrathoracic mass with effusion with mediastinal mass with left sided reticulonodular lesions with cavitating mass in (Figure 1).

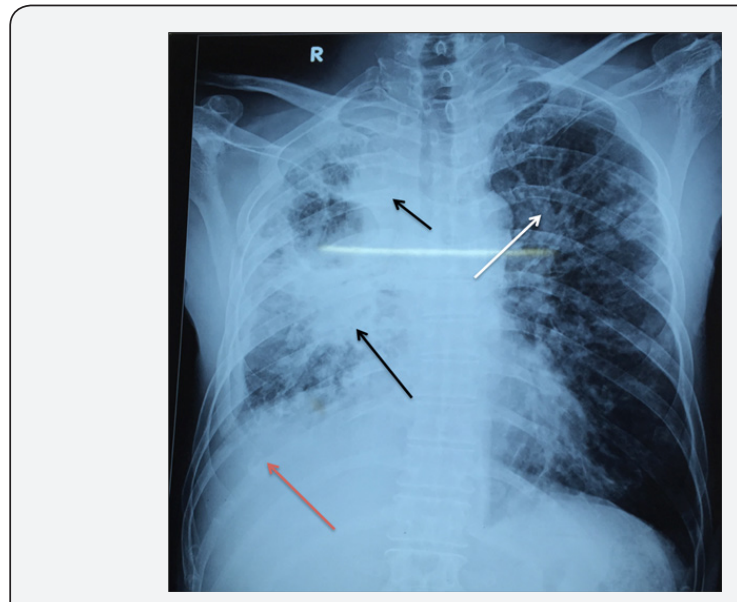

Figure 1: Black arrow shows mediastinal mass and large black arrow explains right sided intrathoracic mass and red arrow in favour of effusion, white arrow shows infiltrates and cavity in left upper lobe. 
Contrast-enhanced computed tomography (CT) chest findings (Figure 2) in mediastinal and lung window showed large non homogenously enhancing, lobulated heterogenous soft tissue mass lesion in anterior superior mediastinum extending to apical segment of right upper lobe with encasement of superior vena cava, right pulmonary artery, abutting trachea with mild displacement toward left. The lesion seen extending up to the right hilum encasing right upper lobe bronchus with collapse, consolidation of right upper lobe suggestive of malignant mediastinal mass (or) lymphoma (or) carcinoma lung.

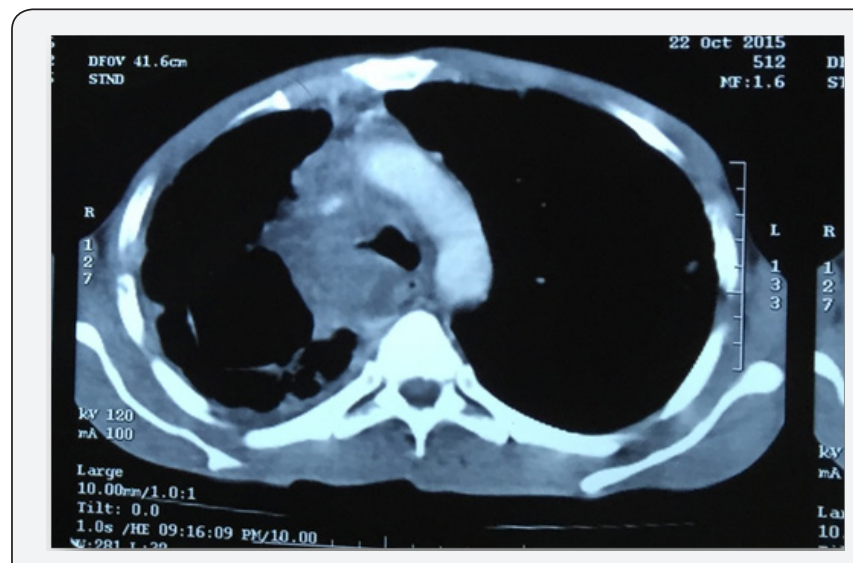

Figure 2: Contrast-enhanced computed tomography (CT) chest findings in mediastinal window showed large non homogenously enhancing, lobulated heterogenous soft tissue mass lesion in anterior superior mediastinum extending to apical segment of right upper lobe.

Patient was subjected for fiberoptic bronchoscopy (FOB) which revealed pedunculated fleshy growth in lower end of the trachea, extending to right main bronchus. Biopsy was taken from pedunculated growth showed lymphocytes, multinucleated giant cells prominent neutrophils, macrophages, Langerhans type giant cells with epithelioid cells with no evidence of malignancy and these findings were suggestive of tuberculosis. On the basis of sputum smear examination and fiber optic bronchoscopy findings and histopathology report tuberculosis diagnosis was made and offered DOTS regimen but he refused so he was put on first line four drugs (Rifampicin, Isoniazid, Ethambutol, Pyrazinamide) Anti-tubercular therapy (ATT). He was discharged after five days initiation of therapy.

\section{Discussion}

Among pulmonary infections mimicking lung malignancy, tuberculosis plays major role approximately in one quarter of patients [4]. Mediastinal mass leading to superior vena cava obstruction is an uncommon presentation of pulmonary tuberculosis. Pulmonary tuberculosis is mostly seen in the forms of cavitary, micro and macronodular and miliary types, fibrocalcifcation and pleural involvement. Pulmonary infiltrates, parenchymal cavitatry lesions along with central mediastinal mass and SVC suggestive of dual pathology like pulmonary tuberculosis with bronchogenic carcinoma. Superior vena cava obstruction is also point out towards malignancy. Fiber optic bronchoscopy (FOB) is a game changer in our case.FOB showed a growth present in right main bronchus covered with caseating material and biopsy from it was in favour of tuberculosis. Superior vena cava syndrome has a distinct clinical presentation and can be life threatening. It is found in $3.8 \%$ of lung cancer patients at the time of diagnosis and more frequently associated with superior vena cava obstruction. 95\% of Superior vena cava syndrome is caused by cancer and rest $5 \%$ of cases could be related to thrombosis, mediastinal fibrosis, infections like syphilis and tuberculosis [5,6]. Superior vena cava syndrome consists of various symptoms due to compression of the SVC. This case is unique because patient presented concomitantly with pulmonary tuberculosis and mediastinal mass. This unusual case of TB mediastinal mass highlights the fact that TB must be kept in mind as a differential diagnosis in patients presenting with superior vena cava obstruction, specially in developing countries in the setting of TB endemics with or without a high prevalence of HIV. A timely diagnosis, high index of suspicion and appropriate treatment lead to immediate relief of the vascular obstruction and often a complete cure.

\section{References}

1. World Health Organization (2015) "Global Tuberculosis Control 2015. WHO, Geneva.

2. Dalar L, Sinem NS, Ahmet LK, Sedat A (2013) Tuberculosis can mimic lung cancer: A case series. Turk Toraks Derg 14: 30-35.

3. Bhatt M, Kant S, Bhaskar R (2012) Pulmonary tuberculosis as differential diagnosis of lung cancer. South Asian J Cancer 1(1): 36-42.

4. Cherian MJ, Dahniya MH, al-Marzouk NF, Abel A, Bader S, et al. (1998) Pulmonary tuberculosis presenting as mass lesions and simulating neoplasms in adults. Australas Radiol 42: 303-308.

5. Wilson LD, Detterbeck FC, Yahalom J (2007) Superior vena cava syndrome with malignant causes. N Engl J Med 356: 1862-1869.

6. Mínguez C, Roca B, González-Miño C, Simón E (2000) Superior vena cava syndrome during the treatment of pulmonary tuberculosis in an HIV-1 infected patient. J Infect 40(2): 187-189. 

(C) (i) This work is licensed under Creative

DOI: 10.19080/IJOPRS.2017.02.555580
Your next submission with Juniper Publishers will reach you the below assets

- Quality Editorial service

- Swift Peer Review

- Reprints availability

- E-prints Service

- Manuscript Podcast for convenient understanding

- Global attainment for your research

- Manuscript accessibility in different formats

( Pdf, E-pub, Full Text, Audio)

- Unceasing customer service

Track the below URL for one-step submission https://juniperpublishers.com/online-submission.php 